\title{
Correction: Impact of sentinel lymph node frozen section evaluation to avoid combined treatment in early-stage cervical cancer
}

Dostalek L, Slama J, Fisherova D, et al. Impact of sentinel lymph node frozen section evaluation to avoid combined treatment in early-stage cervical cancer. Int J Gynecol Cancer Published Online First: 09 April 2020. doi: 10.1136/ijgc-2019-001113.

In this article, the Highlights section was incorrectly changed from:

- Half of lymph node-positive patients are spared from combination of surgery and radiotherapy due to intraoperative sentinel lymph node assessment

- Combined treatment was administered mostly due to the low sensitivity of sentinel lymph node frozen section for the detection of micrometastases

- The second reason was the low accuracy of preoperative imaging in the detection of microscopic parametrial involvement

To

- Half of lymph node-positive patients are spared the combination of surgery and radiotherapy owing to intra-operative sentinel lymph node assessment.

- Combined treatment was given mostly owing to the low sensitivity of the sentinel lymph node frozen section for the detection of micrometastases.

- Combined treatment was also given owing to the low accuracy of pre-operative imaging in the detection of microscopic parametrial involvement.

This has now been corrected in the article.

(C) Author(s) (or their employer(s)) 2020. No commercial re-use. See rights and permissions. Published by BMJ. Int J Gynecol Cancer 2020;30:1087. doi:10.1136/ijgc-2019-001113corr1

D) Check for updates 